\title{
Choroidal neovascularization in angioid streaks following microincision vitrectomy surgery: a case report
}

\author{
Satoshi Katagiri ${ }^{1 *}$, Takaaki Hayashi ${ }^{1}$, Hirotsugu Takashina ${ }^{2}$, Katsuya Mitooka ${ }^{2}$ and Hiroshi Tsuneoka ${ }^{1}$
}

\begin{abstract}
Background: Patients with angioid streaks are prone to developing subretinal hemorrhage after ocular or head injury due to the brittleness of Bruch's membrane. However, there have been no reports of any angioid streak patients in whom choroidal neovascularization occurred after vitrectomy surgery. We report herein a patient with angioid streaks who developed choroidal neovascularization after vitrectomy surgery for epiretinal membrane.
\end{abstract}

Case presentation: A 76-year-old man presented with distorted vision in his left eye, with a best corrected visual acuity of 1.2 and 0.6 in his right and left eyes, respectively. Fundus examination showed angioid streaks in both eyes and epiretinal membrane only in the left eye. The patient underwent 23-gauge three-port pars plana vitrectomy with removal of the epiretinal membrane combined with cataract surgery. Internal limiting membrane in addition to the epiretinal membrane were successfully peeled and removed, with indocyanine green dye used to visualize the internal limiting membrane. His left best corrected visual acuity improved to 0.8. An elevated lesion with retinal hemorrhage due to probable choroidal neovascularization was found between the fovea and the optic disc in the left eye at 7 weeks after surgery. Since best corrected visual acuity decreased to 0.15 and the hemorrhage expanded, posterior sub-Tenon injection of triamcinolone acetonide was performed. However, no improvement was observed. Even though intravitreal bevacizumab injection was performed a total of five times, his best corrected visual acuity remained at 0.1. Subsequently, we performed a combination treatment of a standard-fluence photodynamic therapy and intravitreal ranibizumab injection, with additional intravitreal ranibizumab injections performed 3 times after this combination treatment. Best corrected visual acuity improved to 0.5 and the size of the choroidal neovascularization markedly regressed at 4 months after the combined treatment.

Conclusion: Development of choroidal neovascularization could possibly occur in elderly patients with angioid streaks after vitrectomy surgery. In such cases, a combination of photodynamic therapy and intravitreal ranibizumab injection may be considered for initial treatment of the choroidal neovascularization.

Keywords: Angioid streaks, Choroidal neovascularization, Vitrectomy surgery, Anti-vascular endothelial growth factor treatment, Photodynamic therapy, Pseudoxanthoma elasticum

\footnotetext{
* Correspondence: ktgr_two_ai@icloud.com

${ }^{1}$ Department of Ophthalmology, The Jikei University School of Medicine,

3-25-8 Nishi-shimbashi, Minato-ku, Tokyo 105-8461, Japan

Full list of author information is available at the end of the article
} 


\section{Background}

Angioid streaks (AS) are visible irregular crack-like dehiscences radiating from the optic nerve to the peripheral retina. Approximately $70 \%$ of AS patients have pseudoxanthoma elasticum (PXE) characterized by changes in the elastic tissue of the skin [1]. Patients with AS are usually asymptomatic unless the lesions extend towards the fovea or develop complications such as traumatic Bruch's membrane rupture or choroidal neovascularization $(\mathrm{CNV})$. Several studies on the relationship between ocular trauma and subretinal hemorrhage in patients with AS have been reported $[2,3]$. There is also a report of an AS patient who developed $\mathrm{CNV}$ after indirect trauma to the eye itself [4]. It has also been reported that $15 \%$ of AS patients who suffer head injuries develop significant visual impairment [5]. However, to our knowledge, there have been no reports of any AS patients in whom $\mathrm{CNV}$ occurred after vitrectomy surgery.

We report herein a case of an AS patient in whom $\mathrm{CNV}$ occurred at 7 weeks after microincision vitrectomy surgery for removal of epiretinal membrane (ERM).

\section{Case presentation}

A 76-year-old male patient with a medical history of hypertension but no eye surgery reported distorted vision in the left eye. Best corrected visual acuity (BCVA) at his initial examination was 1.2 (with +1.75 diopter (dpt), cylinder (cyl) $-1.25 \mathrm{dpt}$ Ax $110^{\circ}$ ) in his right eye and 0.6 (with $+2.75 \mathrm{dpt}$, cyl. $-1.50 \mathrm{dpt} \mathrm{Ax} 90^{\circ}$ ) in his left eye. Using the IOLMaster 500 (Carl Zeiss Meditec AG, Dublin, CA, USA), his axial lengths were determined to be 23.3 and $23.1 \mathrm{~mm}$ in his right and left eyes, respectively. Except for mild senile cataracts in the anterior segments and media of both of his eyes, there were no abnormalities found. Intraocular pressures were 13 $\mathrm{mmHg}$ on the right and $11 \mathrm{mmHg}$ on the left. Fundus examination showed ERM in the left eye, in addition to bilateral AS. Although spectral-domain optical coherence tomography (OCT; Cirrus HD-OCT, Carl Zeiss Meditec AG) using the high-definition 5-line raster scan protocol (horizontal scan of $6 \mathrm{~mm}$ ) revealed ERM, CNV was not observed in the macula of his left eye (Figure 1a). The patient subsequently underwent 23-gauge threeport pars plana vitrectomy with removal of ERM combined with cataract surgery at The Jikei University, Daisan Hospital. Indocyanine green dye was used to visualize the internal limiting membrane (ILM). The ILM in addition to the ERM were successfully peeled and removed (Figure 1b). No retinal hemorrhage was noted during the vitreous surgery (Figure 1b), and his left BCVA subsequently improved to 0.8 .

Seven weeks after the vitrectomy surgery, an elevated lesion with retinal hemorrhage due to probable $\mathrm{CNV}$

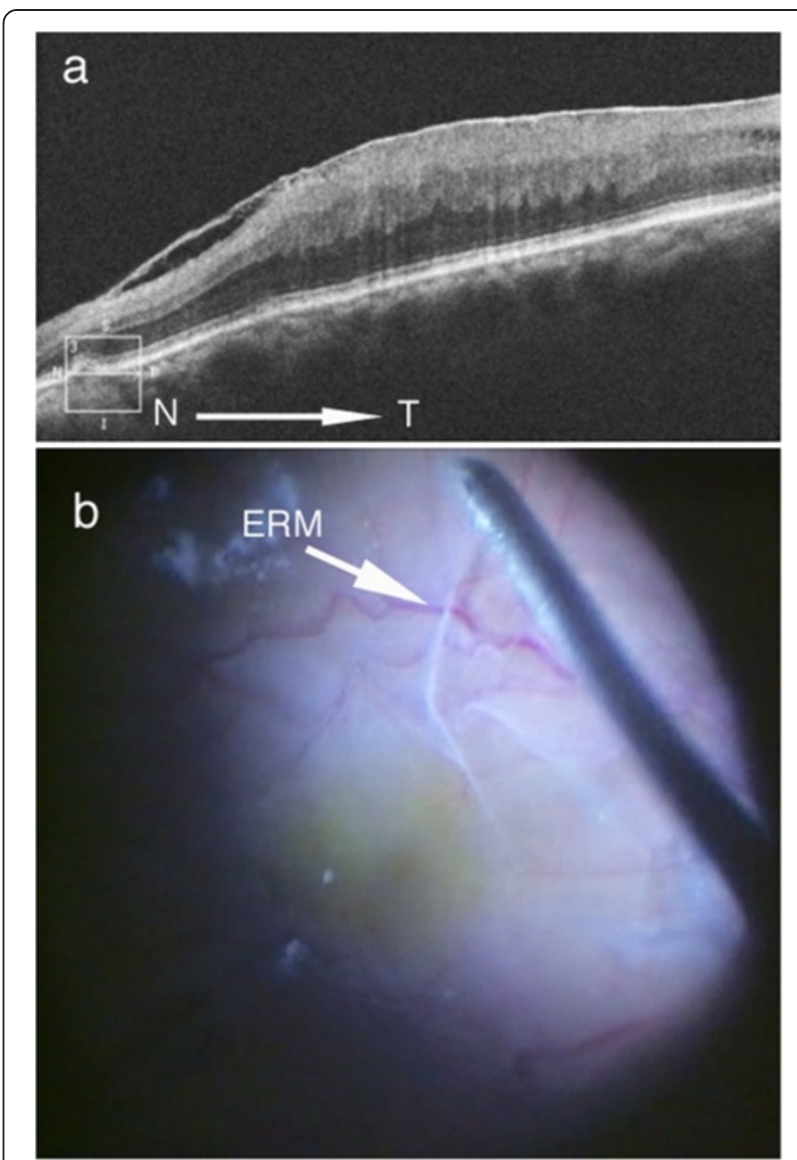

Figure 1 Optical coherence tomography before surgery and fundus photograph of patient during vitrectomy surgery. a) Epiretinal membrane (ERM) in optic coherence tomography before vitrectomy surgery. b) Fundus photograph during vitrectomy surgery. The ERM is successfully peeled before ILM peeling.

was found between the fovea and the optic disc in his left eye (Figure 2), although he had no history of any ocular trauma after the surgery. One week later, his left BCVA decreased to 0.15 and the retinal hemorrhage expanded. Although posterior sub-Tenon injection of triamcinolone acetonide was performed, no visual improvement was seen.

At 12 weeks after the vitrectomy surgery at The Jikei University Hospital, his BCVA was 0.08 in his left eye. Fundus examination revealed a radiating dark brownish line from the optic disc head in his right (Figure 3a) and left (Figure 3b) eyes, and there was an elevated subretinal lesion with retinal hemorrhage in his left macula (Figure 3b). Although OCT showed no abnormal findings in his right eye (Figure 3c), Gass type $2 \mathrm{CNV}$ with macular edema was observed in his left eye (Figure 3d). Fluorescein angiography (FA) revealed well-defined (classic) CNV from the early (Figure 3e) to late phases (Figure 3f) in the left macula. Using indocyanine green angiography (ICGA), we were able 


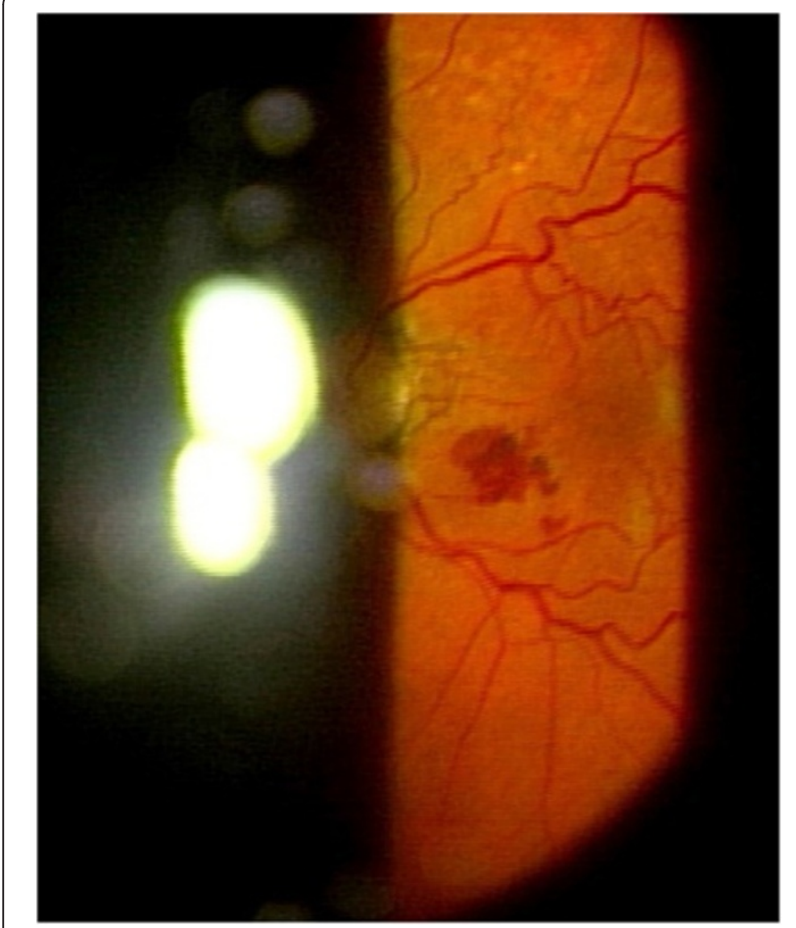

Figure $\mathbf{2}$ Left fundus finding $\mathbf{7}$ weeks after the vitrectomy surgery. Photograph shows an elevated lesion with retinal hemorrhage that is most likely due to probable choroidal neovascularization found between the fovea and the optic disc.

to visualize the $\mathrm{CNV}$ from the early (Figure $3 \mathrm{~g}$ ) to late phases (Figure $3 \mathrm{~h}$ ).

Over the next 6 months, a total of 5-time intravitreal injections of the anti-vascular endothelial growth factor (VEGF) drug, bevacizumab (Avastin, Genentech, San Francisco, CA, USA), were given. His left BCVA remained at 0.1 . Fundus examination demonstrated that there was no regression of the CNV (Figure 4a), as was confirmed by OCT (Figure 4b). The FA images indicated there was a foveal lesion with evidence of classic CNV in the early phase (Figure 4c) and an extended high fluorescent lesion in the late phase (Figure 4d).

Subsequently, we performed standard-fluence photodynamic therapy (PDT: laser fluence set at $50 \mathrm{~J} / \mathrm{cm}^{2}$ ) with full-dose verteporfin (Visudyne; Novartis Pharma AG, Basel, Switzerland) in combination with an intravitreal ranibizumab (Lucentis, Genentech) (IVR) injection. After this combination treatment, 3 additional IVR treatments were performed. At 4 months after the combination treatment, his BCVA improved to 0.5. There was a marked regression of the CNV size observed in both the fundus (Figure 5a). OCT showed significant but incomplete regression of $\mathrm{CNV}$, and persistence of intra-retinal cysts (Figure 5b). The FA images revealed that leakage from the $\mathrm{CNV}$ noted in the early phases (Figure 5c) almost completely disappeared by the late phases (Figure $5 \mathrm{~d}$ ).

Examination of the skin on the neck showed suggestive of PXE. A skin biopsy was performed from the lesion on the neck. The histological section of the biopsy revealed short and broken elastic fibers with dark staining of calcium deposits by Von Kossa staining in the reticular dermis (Figure 6), convincing a diagnosis of PXE.

\section{Discussion}

In this report, we describe a single AS patient in whom CNV developed 7 weeks after vitrectomy surgery for ERM. To date, there have been no other reports of any AS patients who have developed CNV after vitrectomy surgery.

Numerous studies have reported the incidence of $\mathrm{CNV}$ to vary between $72 \%-86 \%$ in AS patients [5]. It is reported that the risk of developing $\mathrm{CNV}$ increases with age [6]. Other risk factors comprise the width, length and location of the AS. Several studies have reported that wider and longer AS are associated with higher risk of $\mathrm{CNV}$, and that the risk of CNV development is especially higher if AS are located within one optic disc diameter from the foveola $[5,7,8]$.

As an external factor, ocular trauma can be a risk factor for the development of subretinal hemorrhage $[2,3]$. In fact, AS patients are likely to develop breaks of Bruch's membrane even after relatively mild ocular head injuries, since their Bruch's membrane is brittle [5]. In addition, it has also been reported that an AS patient developed CNV 4 months after an indirect ocular trauma [4]. Thus, it is possible that CNV can occur due to either direct or indirect ocular trauma.

Regarding the relationship between vitrectomy surgery and $\mathrm{CNV}$ development, there have been some studies that have reported finding CNV after vitrectomy surgery for idiopathic macular hole [9-12]. Although the pathogenesis underlying the development of CNV after macular hole surgery has yet to be completely clarified, it has been suggested that the most plausible explanation is an age-related degenerative change in the retinal pigment epithelium (RPE) and Bruch's membrane. This is supported by the fact that there is a higher prevalence of $\mathrm{CNV}$ development after macular hole surgery in older patients [10,13]. In addition, as has been reported in a previous study, mechanical trauma during the ILM peeling in the macular hole surgery might have played a role in the pathogenesis of the CNV that subsequently developed in the patient [10]. In fact, this is similar to the current case, as our patient had brittleness of Bruch's membrane and RPE because of AS and aging and thus, underwent vitrectomy surgery with ERM and ILM peeling, after which he developed CNV. 

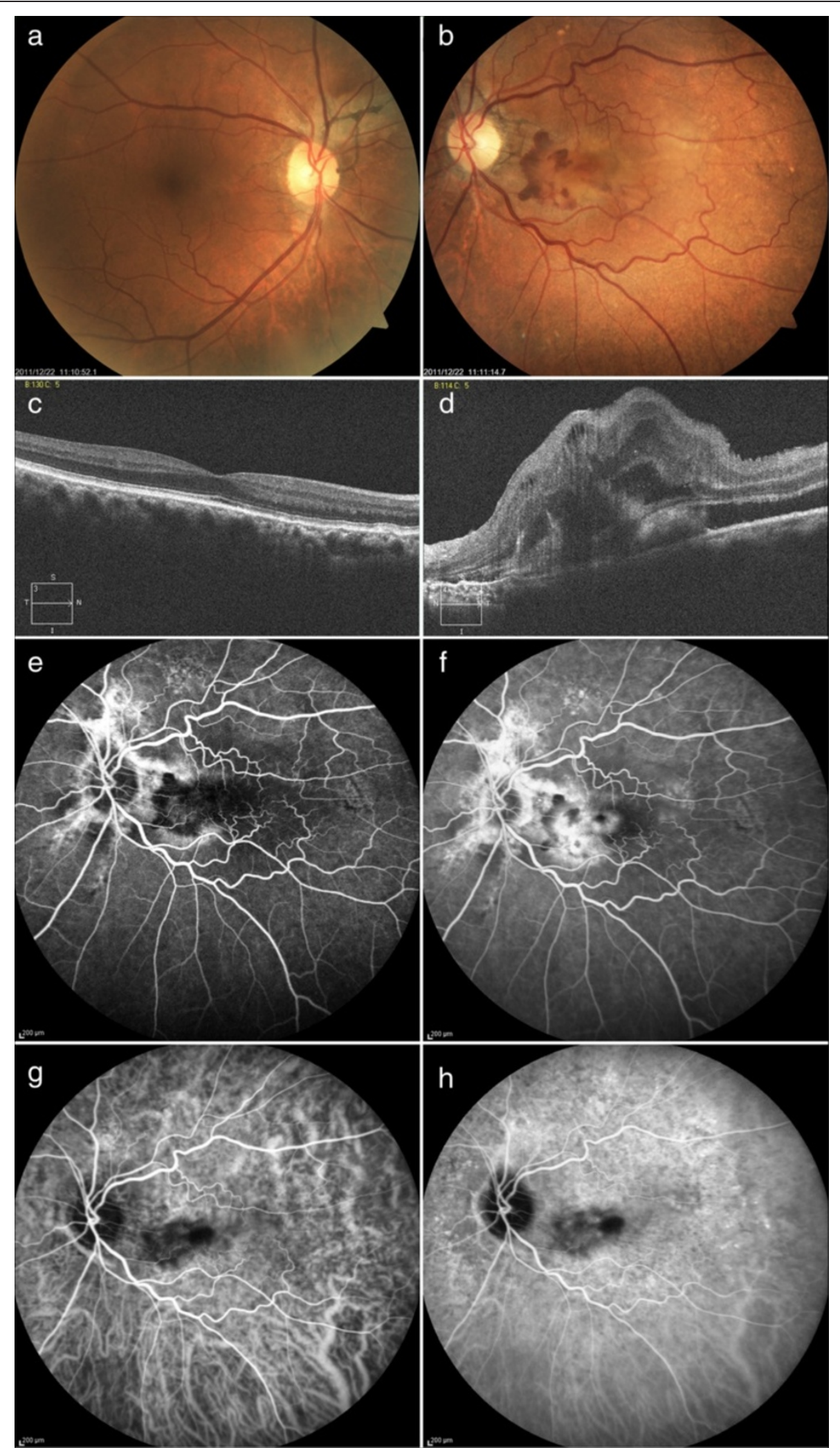

Figure $\mathbf{3}$ (See legend on next page.) 
(See figure on previous page.)

Figure 3 Fundus findings prior to the initial anti-vascular endothelial growth factor therapy. a, b) Fundus photographs show angioid streaks in the right (a) and left (b) eyes and choroidal neovascularization (CNV) in the left macula (b). $\mathbf{c}$, d) Optical coherence tomography shows no abnormal finding in the right eye (c) and Gass type 2 CNV with macular edema in the left eye (d). e, f) Fluorescein angiograms show welldefined (classic) CNV in the early (e) to late phases (f) in the left macula. $\mathbf{g}, \mathbf{h}$ ) Indocyanine green angiograms show CNV is visualized from the early $(\mathbf{g})$ to late phases $(\mathbf{h})$ in the left macula.

When treating CNV secondary to AS, previous studies have described the use of monotherapy treatments employing PDT or anti-VEGF therapies. For example, Arias et al. reported that PDT was not effective in the treatment of CNV in the macula [14], while Browning et al. showed that PDT delayed, but did not permanently prevent visual loss associated with the CNV in AS [15]. However, in other cases it has been reported that injection of intravitreal bevacizumab (IVB) was effective as a long-term control tool for $\mathrm{CNV}$ associated with AS [16,17]. Moreover, it has been reported that IVR was also effective in treating $\mathrm{CNV}$ associated with AS [18-20]. Even so, after the patient in the current case received 5-time IVB injections, the CNV remained active. This suggested that there was a decrease in the biologic effect after repeated intravitreal anti-VEGF injections of the same drug, such as bevacizumab [21-23]. An in vitro experiment demonstrated that the absence or presence of hyaluronan, which is a major component in the vitreous body, may be associated with the clinical efficacy of IVB because of the higher affinity of hyaluronan for bevacizumab as compared to that for ranibizumab [24]. Christoforidis et al. revealed that clearance rates for intravitreally placed bevacizumab or ranibizumab in vitrectomized or lensectomized rabbit model eyes are faster than those
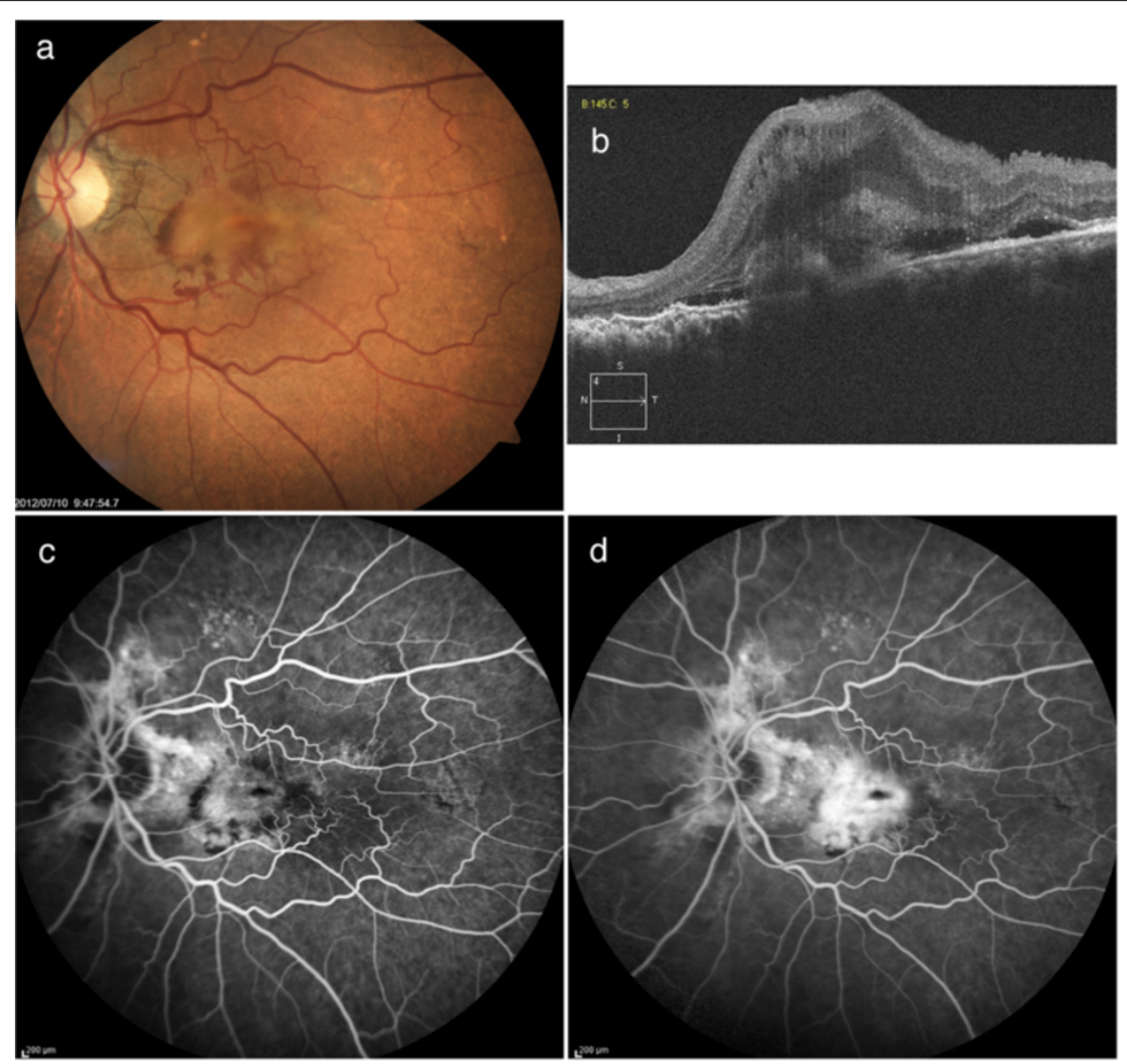

Figure 4 Left fundus findings after 5 intravitreal bevacizumab injections. a) Fundus photograph indicates there is no regression of the choroidal neovascularization (CNV). b) Optical coherence tomography also confirms there is no regression of the CNV. c, d) Fluorescein angiograms show evidence of classic CNV in the early (c) to the late phases (d). 

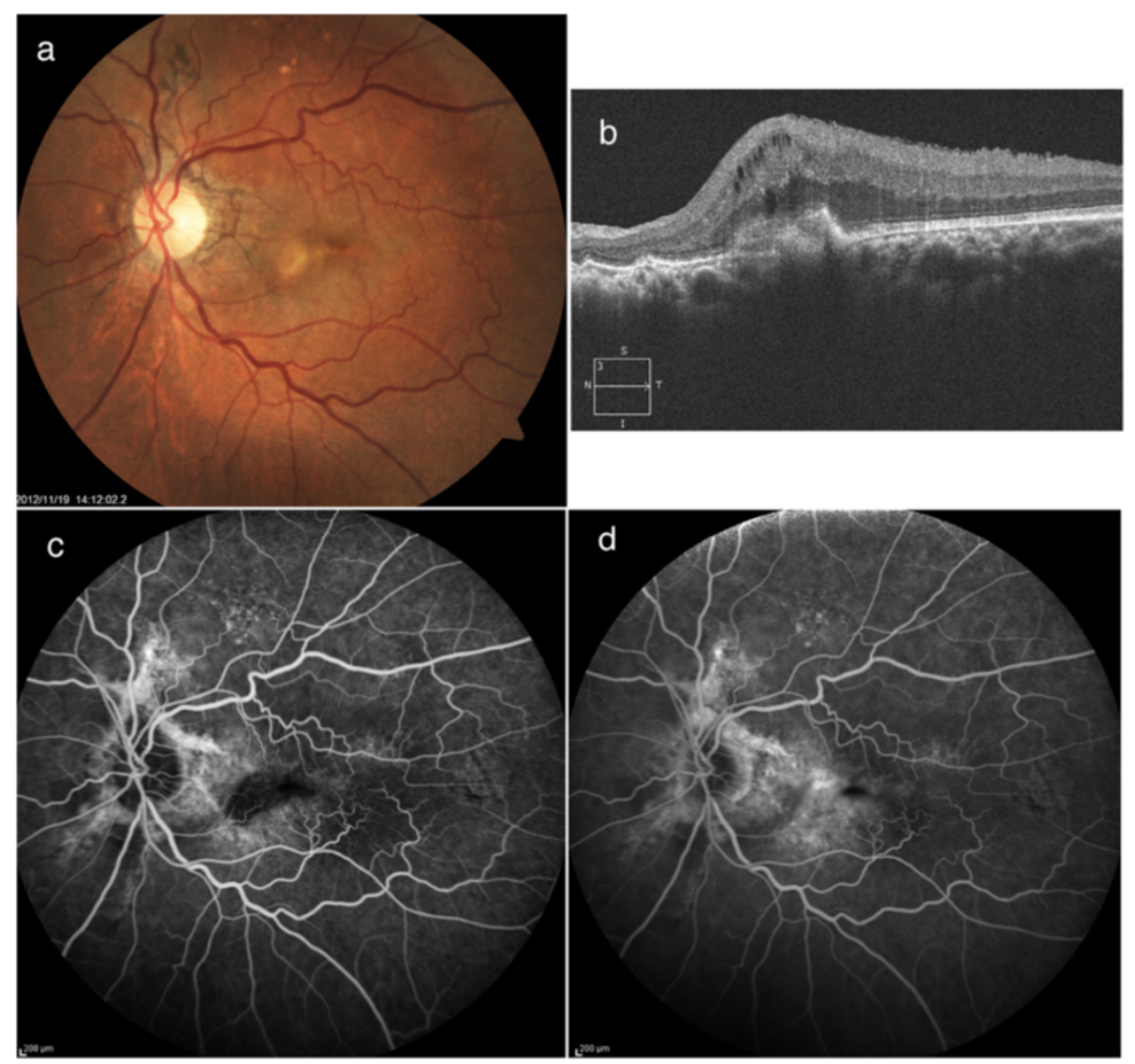

Figure $\mathbf{5}$ Left fundus findings $\mathbf{4}$ months after the combination treatment. a) Fundus photograph shows marked regression of the choroidal neovascularization (CNV). b) Optical coherence tomography shows significant but incomplete regression of CNV, and persistence of intra-retinal cysts. c, d) Fluorescein angiograms show that leakage from the CNV almost completely disappears between the early (c) and late phases (d).

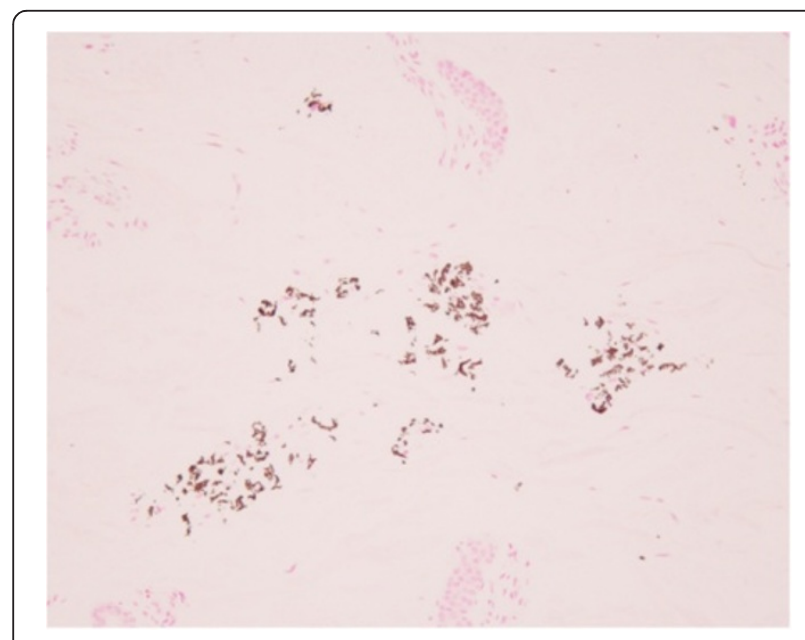

Figure 6 Histological findings of a skin biopsy on the neck. The histological section reveals short and broken elastic fibers with dark staining of calcium deposits by Von Kossa staining in the reticular dermis, convincing a diagnosis of pseudoxanthoma elasticum. in control eyes [25]. Based on these previous findings in conjunction with the bevacizumab tachyphylaxis and the vitrectomized-pseudophakic condition that was present, we decided to use ranibizumab instead of bevacizumab in all of the subsequent treatments for this patient. Recently, it has been reported that the combination of IVR and reduced-fluence PDT for $\mathrm{CNV}$ associated with AS was effective in the regression of $\mathrm{CNV}$ and in improving (or stabilizing) the visual acuity [26,27]. Based on the above-mentioned findings, we performed the combined therapy of fulldose PDT and IVR instead of IVR monotherapy. Our current results support the effectiveness of the combined therapy, as the combination therapy of full-dose PDT and IVR was effective, with improvement of the visual acuity and regression of the $\mathrm{CNV}$ ultimately seen in our patient.

\section{Conclusions}

Development of CNV can occur in elderly patients with AS after vitrectomy surgery. In such cases, the combination of 
PDT and anti-VEGF therapies may be considered for use as the initial treatment of $\mathrm{CNV}$.

\section{Consent}

Written informed consent was obtained from the patient for publication of this case report and any accompanying images. A copy of the written consent is available for review by the Editor of this journal.

\section{Competing interests}

The authors declare that they have no competing interests.

\section{Authors' contributions}

SK drafted the manuscript and reviewed the literature. TH examined and managed the patient and critically analyzed the manuscript. HT examined and managed the patient. KM offered valuable insight into the treatment of the patient. HT offered valuable insight into the treatment of the patient and critically analyzed the manuscript. All authors read and approved the final manuscript.

\section{Acknowledgements}

This study was supported by grants from the Ministry of Health, Labor and Welfare of Japan (T.H.) and the Vehicle Racing Commemorative Foundation (T.H.).

\section{Author details}

'Department of Ophthalmology, The Jikei University School of Medicine, 3-25-8 Nishi-shimbashi, Minato-ku, Tokyo 105-8461, Japan. ${ }^{2}$ Department of Ophthalmology, Daisan Hospital, The Jikei University School of Medicine, Tokyo, Japan.

Received: 25 December 2012 Accepted: 2 July 2013

Published: 5 July 2013

\section{References}

1. Connor PJ Jr, Juergens JL, Perry HO, Hollenhorst RW, Edwards JE: Pseudoxanthoma elasticum and angioid streaks. A review of 106 cases. Am J Med 1961, 30:537-543.

2. Britten MJ: Unusual traumatic retinal haemorrhages associated with angioid streaks. Br J Ophthalmol 1966, 50:540-542.

3. Levin DB, Bell DK: Traumatic retinal hemorrhages with angioid streaks. Arch Ophthalmol 1977, 95:1072-1073.

4. Pandolfo A, Verrastro G, Piccolino FC: Retinal hemorrhages following indirect ocular trauma in a patient with angioid streaks. Retina 2002, 22:830-831.

5. Georgalas I, Papaconstantinou D, Koutsandrea C, Kalantzis G, Karagiannis D, Georgopoulos G, Ladas I: Angioid streaks, clinical course, complications, and current therapeutic management. Ther Clin Risk Manag 2009, 5:81-89.

6. Shilling JS, Blach RK: Prognosis and therapy of angioid streaks. Trans Ophthalmol Soc U K 1975, 95:301-306.

7. Mansour AM, Ansari NH, Shields JA, Annesley WH Jr, Cronin CM, Stock EL: Evolution of angioid streaks. Ophthalmologica 1993, 207:57-61.

8. Mansour AM, Shields JA, Annesley WH, el-Baba F Jr, Tasman W, Tomer TL: Macular degeneration in angioid streaks. Ophthalmologica 1988, 197:36-41.

9. Natarajan S, Mehta HB, Mahapatra SK, Sharma S: A rare case of choroidal neovascularization following macular hole surgery. Graefes Arch Clin Exp Ophthalmol 2006, 244:271-273.

10. Oh HN, Lee JE, Kim HW, Yang JW, Yun IH: Occult choroidal neovascularization after successful macular hole surgery treated with ranibizumab. Clin Ophthalmol 2012, 6:1287-1291.

11. Tabandeh H, Smiddy WE: Choroidal neovascularization following macular hole surgery. Retina 1999, 19:414-417.

12. Berinstein DM, Hassan TS, Williams GA, Margherio RR, Ruby AJ, Garretson BR: Surgical repair of full-thickness idiopathic macular holes associated with significant macular drusen. Ophthalmology 2000, 107:2233-2239.

13. Tabandeh H, Smiddy WE, Sullivan PM, Monshizadeh R, Rafiei N, Cheng L, Freeman W: Characteristics and outcomes of choroidal neovascularization occurring after macular hole surgery. Retina 2004, 24:714-720.

14. Arias $L$, Pujol O, Rubio M, Caminal J: Long-term results of photodynamic therapy for the treatment of choroidal neovascularization secondary to angioid streaks. Graefes Arch Clin Exp Ophthalmol 2006, 244:753-757.

15. Browning AC, Chung AK, Ghanchi F, Harding SP, Musadiq M, Talks SJ, Yang YC, Amoaku WM, United Kingdom PDTUG: Verteporfin photodynamic therapy of choroidal neovascularization in angioid streaks: one-year results of a prospective case series. Ophthalmology 2005, 112:1227-1231.

16. Teixeira A, Moraes N, Farah ME, Bonomo PP: Choroidal neovascularization treated with intravitreal injection of bevacizumab (Avastin) in angioid streaks. Acta Ophthalmol Scand 2006, 84:835-836.

17. Derriman L, Marshall J, Moorman C, Downes SM: The use of intravitreal bevacizumab to treat choroidal neovascular membranes (CNVMs). Retina 2008, 28:910. author reply 910-911.

18. Mimoun G, Tilleul J, Leys A, Coscas G, Soubrane G, Souied EH: Intravitreal ranibizumab for choroidal neovascularization in angioid streaks. Am J Ophthalmol 2010, 150:692-700. e691.

19. Kang S, Roh YJ: Intravitreal ranibizumab for choroidal neovascularisation secondary to angioid streaks. Eye (Lond) 2009, 23:1750-1751.

20. Shah M, Amoaku WM: Intravitreal ranibizumab for the treatment of choroidal neovascularisation secondary to angioid streaks. Eye (Lond) 2012, 26:1194-1198.

21. Schaal S, Kaplan HJ, Tezel TH: Is there tachyphylaxis to intravitreal antivascular endothelial growth factor pharmacotherapy in age-related macular degeneration? Ophthalmology 2008, 115:2199-2205.

22. Keane PA, Liakopoulos S, Ongchin SC, Heussen FM, Msutta S, Chang KT, Walsh AC, Sadda SR: Quantitative subanalysis of optical coherence tomography after treatment with ranibizumab for neovascular age-related macular degeneration. Invest Ophthalmol Vis Sci 2008, 49:3115-3120.

23. Gasperini JL, Fawzi AA, Khondkaryan A, Lam L, Chong LP, Eliott D, Walsh AC, Hwang J, Sadda SR: Bevacizumab and ranibizumab tachyphylaxis in the treatment of choroidal neovascularisation. Br J Ophthalmol 2012, 96:14-20.

24. Sugita I, Yoneda M, Iwaki M, Zako M: Comparative Analysis of Hyaluronan's Affinity for Antivascular Endothelial Growth Factor Agents. Ophthalmic Res 2012, 49:43-48.

25. Christoforidis JB, Williams MM, Wang J, Jiang A, Pratt C, Abdel-Rasoul M, Hinkle GH, Knopp MV: Anatomic and pharmacokinetic properties of intravitreal bevacizumab and ranibizumab after vitrectomy and lensectomy. Retina 2013, 33:946-952.

26. Prabhu W, Morris RJ, Shah PK, Narendran V: Combination treatment of low fluence photodynamic therapy and intravitreal ranibizumab for choroidal neovascular membrane secondary to angioid streaks in Paget's disease - 12 month results. Indian J Ophthalmol 2011, 59:306-308.

27. Artunay O, Yuzbasioglu E, Rasier R, Sengul A, Senel A, Bahcecioglu H: Combination treatment with intravitreal injection of ranibizumab and reduced fluence photodynamic therapy for choroidal neovascularization secondary to angioid streaks: preliminary clinical results of 12-month follow-up. Retina 2011, 31:1279-1286

doi:10.1186/1471-2415-13-29

Cite this article as: Katagiri et al:: Choroidal neovascularization in angioid streaks following microincision vitrectomy surgery: a case report. $B M C$ Ophthalmology 2013 13:29.

\section{Submit your next manuscript to BioMed Central and take full advantage of:}

- Convenient online submission

- Thorough peer review

- No space constraints or color figure charges

- Immediate publication on acceptance

- Inclusion in PubMed, CAS, Scopus and Google Scholar

- Research which is freely available for redistribution 